\title{
Revisitando as Origens da 'Arte Dentária': O Processo Histórico e o Modelo Hegemônico de Prática Odontológica em Análise ${ }^{1}$
}

\author{
LUCIETTO, Deison Alencar* \\ ZARDIN, Nara Rúbia** \\ PRETTO, Salete Maria*** \\ SLAVUTZKY, Sonia Maria Blauth de****
}

\begin{abstract}
RESUMO
Este artigo tem como objetivo principal revisar e descrever acontecimentos intrínsecos à gênese da profissão de cirurgião-dentista, elucidando dimensões e desdobramentos atuais em torno da 'Arte Dentária'. Busca-se, com isso, refletir sobre limites e avanços da práxis odontológica e, ao mesmo tempo, questionar alguns de seus aspectos que se interpõem como dificultadores para a consolidação de uma atenção em saúde pautada em princípios de eqüidade, de humanização e de integralidade. $\mathrm{O}$ texto, de caráter informativo-descritivo, analisa eventos do processo histórico da Odontologia no ocidente e no Brasil, especificamente. Além disso, problematiza dimensões do modelo hegemônico de prática odontológica, no cenário nacional atual, evidenciando 'nós críticos', os quais precisam, com certa urgência, ser percebidos, analisados e enfrentados pela classe odontológica, uma vez que alguns deles se caracterizam como dilemas que acompanham a profissão desde sua origem. A superação de tais situações dilemáticas torna-se imprescindível para a construção de nova postura no cuidado em saúde bucal e para que a Odontologia, possa, de fato, alcançar os seus objetivos enquanto profissão.
\end{abstract}

\section{PALAVRAS-CHAVE:}

Odontologia. Profissão. Processo histórico da odontologia. Modelo hegemônico de prática odontológica.

\section{INTRODUÇÃO}

Conhecer um pouco mais acerca do desenvolvimento da Odontologia e de seu modelo de prática atual remete a, invariavelmente, olhar para sua origem, mesmo que de forma breve. Há que se ter em mente, entretanto, que os acontecimentos passados, ou seja, aqueles que se referem às origens da profissão, não podem ser considerados como os determinantes únicos do seu comportamento atual, afirmando-se que não há uma "evolução natural" (ou sucessão natural) de acontecimentos. Assim sendo, as mudanças que acontecem na sociedade influenciam no presente e projetam novas conformações para o futuro, havendo espaço para avanços, retrocessos, contradições, disputas e questionamentos, isto é, um tempo-espaço não linear. Alguns autores têm trazido importantes informações sobre o proces- so histórico que resultou no surgimento da profissão de cirurgião-dentista no ocidente e no Brasil, especificamente (CHAVES, 1986; PERRI DE CARVALHO, 1995; RING, 1998; BOTAZZO, 2000; FREITAS, 2001; NARVAI, 2002; FERNANDES NETO, 2003; CARVALHO, 2003). Este texto se propõe a problematizar alguns aspectos históricos da organização de um corpo de saberes e práticas, [os quais se destinam, ao menos discursivamente, em proporcionar saúde à população,] em torno do campo biológico circunscrito anatomicamente entre face e pescoço, trazendo informações para aqueles que se dedicam ao exercício da "arte dentária". Busca-se, ao visualizar acontecimentos passados, fornecer subsídios para o entendimento dos elementos que caracterizam a prática odontológica vigente na sociedade brasileira deste início de século.

\section{ASPECTOS HISTÓRICOS DO DESENVOLVIMENTO DA ODONTOLOGIA}

As profissões são criadas nas sociedades a partir de determinadas necessidades (IYDA; 1998; NARVAI, 1999; BOTAZZO, 2000; CARVALHO 2003) que, uma vez estabelecidas, determinam o surgimento de serviços que possuam algum grau de eficiência e de regularidade de oferta ${ }^{2}$. Com a Odontologia não foi diferente. Assim, a "profissionalização da atividade só se efetivou a partir da necessidade dos próprios homens de negarem uma realidade agressiva e adversa" (IYDA, 1998:132). Neste mesmo sentido, Ring (1998) coloca que "a Odontologia se converteu em uma disciplina científica independente, não da noite para o dia, mas depois de muitas experiências dolorosas e denodada entrega por parte de várias gerações de profissionais" (RING, 1998:157).

\footnotetext{
${ }^{1}$ Este texto foi composto a partir de referenciais discutidos na dissertação de mestrado intitulada "Percepções dos Docentes e Reflexões sobre o Processo de Formação dos Estudantes de Odontologia”, apresentada à Escola Nacional de Saúde Pública Sérgio Arouca-ENSP/ FIOCRUZ (2005).

${ }^{2}$ De acordo com Carvalho (2003), uma profissão pode ser vista enquanto "um conjunto de características e funções sociais" (CARVALHO, 2003:18). Tomando por base alguns dos estudos revisados pela autora, podem ser destacadas as seguintes características das profissões: monopólio de habilidades, treinamento padronizado, competência numa área específica, existência de aparatos de auto-regulação, autonomia técnica, status social, ocupação e dedicação dos membros, produção de conhecimentos e competências, busca pela solução de problemas relevantes e controle do campo de trabalho, dentre outros.
}

*Cirurgião-Dentista pela UFSM. Mestre em Saúde Pública pela ENSP/FIOCRUZ. Professor Substituto do Departamento de Odontologia Preventiva e Social da FO-UFRGS

**Cirurgiã-Dentista pela UPF. Mestre em Gestão da Educação pela PUCRS. Membro do GP em Comunicação Institucional e Organizacional-

UFSM. Mestranda em Administração- UFSM. Professora do Curso de Especialização em Odontologia em Saúde Coletiva da ABO-RS ***Cirurgiã-Dentista pela PUCRS. Mestre em Odontopediatria pela PUCRS. Doutora em Odontologia Social pela UFF. Coordenadora do Curso de Especialização em Odontologia em Saúde Coletiva da ABO-RS ****Cirurgia-Dentista pela UFRGS. Mestre em Educação e Comunicação Universidade de Pittsburgh. Mestre em Odontologia Social UFRGS. Doutora em Odontologia Social UFF 
Carvalho (2003) destaca algumas razões pelas quais a Odontologia se tornou uma profissão independente: (1) a expansão e transformação do mercado de consumo de serviços odontológicos, estimulada pela disseminação das doenças bucais, especialmente da cárie dentária, na primeira metade do século XIX; (2) a existência de condições técnicas e econômicas em torno da prática odontológica do século XIX; (3) a proliferação de diferentes grupos de praticantes de Odontologia, qualificados e desqualificados na "arte dental", e as disputas pelo controle do mercado de serviços odontológicos; (4) o desenvolvimento de uma noção utilitária de Odontologia e a luta para a obtenção de reconhecimento público; bem como (5) as descobertas relacionadas ao campo da Odontologia e o desenvolvimento de teorias científicas sobre os problemas dos dentes e da boca (CARVALHO, 2003).

Tem sido relatado que as doenças bucais acompanham o homem desde tempos muito remotos (BEZERRA DE TOLEDO, 1999), sendo observados, em crânios do homem pré-histórico, vestígios das doenças cárie e periodontal, as duas enfermidades que ainda hoje acometem a maior parte da população. Diferentes tratamentos para estas doenças foram propostos ao longo dos tempos, como o uso de poções mágicas, de feitiçarias, de ervas etc., até o desenvolvimento de técnicas e tecnologias mais avançadas, principalmente, a partir do século XIX e início do século XX.

Freitas (2001) afirma que uma mudança no perfil da cárie dentária, de uma doença indolor para uma afeç̧ão violenta e muito dolorosa, principalmente a partir de mudanças drásticas nos padrões dietéticos, com o advento do consumo do açúcar (a partir do século XVI) foi uma das molas propulsoras para a organização de um corpo de práticas e de conhecimentos que viriam a originar futuramente a profissão de cirurgião-dentista.

Neste mesmo sentido, Carvalho (2003), ao analisar a profissionalização da Odontologia no ocidente, afirma que a emergência e a consolidação do mercado de serviços odontológicos (séculos XVIII e XIX, respectivamente) estão relacionadas com o crescente consumo de açúcar na sociedade ocidental. Esta visão é encontrada também em Iyda (1998), a qual afirma que as experiências humanas com a dor e com as dificuldades de mastigação estão no princípio do surgimento da Odontologia como atividade específica (IYDA, 1998).

Hoje existe clareza de que a dieta é um dos fatores determinantes envolvidos no surgimento e na progressão da doença cárie. Em estudo de revisão sobre quantidade de açúcar e cárie, conduzido por Sheiham ${ }^{3}$ apud Freire (2000:262), ficou destacado que uma disponibilidade superior de açúcar de 10-15 $\mathrm{kg}$ por pessoa por ano está relacionada com um aumento do índice de cárie ${ }^{3}$.

No início do século XVII o acesso ao açúcar esteve circunscrito aos nobres e ricos, pois este produto era considerado um artigo de luxo. Somente a partir do século XIX o açúcar passou a ser consumido em massa, ou seja, pelos estratos populacionais menos favorecidos ${ }^{4}$. Observa-se que houve uma distribuição semelhante entre o acesso/consumo do açúcar e a disseminação da cárie dental: inicialmente a doença esteve circunscrita aos ricos e nobres e, posteriormente, a partir do século XIX, passou a atingir a população de maneira indistinta. Além disso, concomitantemente, a doença cárie tornou-se mais severa, apresentando sintomatologia dolorosa típica, com episódios de dores agudas e de rápida destruição das estruturas mineralizadas dos dentes (CARVALHO, 2003).

A disseminação da doença cárie dental na população, independentemente da condição econômica, e a conseqüente necessidade por tratamento passou a constituir uma demanda crescente por alguma resposta em termos de serviços odontológicos, requerendo profissionais que pudessem resolver os problemas dos "dentes" e da "boca".

O desenvolvimento da Odontologia moderna, enquanto profissão independente, está intimamente relacionado a alguns fatos ocorridos na França, entre o final do século XVII e início do século XVIII e, nos Estados Unidos, principalmente a partir da metade do século XIX. Assim sendo, afirma-se que, na Idade Média Européia, os responsáveis pelo tratamento dos dentes eram os cirurgiões-barbeiros (RING, 1998).

Durante o século XVII, os prestadores de serviços odontológicos eram procurados com a finalidade de aliviar a dor de dente e o sofrimento dela decorrente. Estes episódios eram tratados principalmente por meio das extrações dos elementos dentais comprometidos pela doença cárie. Nesta época, a substituição dos dentes extraídos não era considerada essencial (CARVALHO, 2003).

Ring (1998) relata que, desde o final do século XVII, já havia, na França, uma preocupação das autoridades sobre a qualificação daqueles que se ocupavam do exercício da Odontologia. Desta forma, este autor relata que, já no ano de 1699 , o Parlamento Francês aprovou uma lei estipulando que os dentistas (experts pour les dents), juntamente com os outros especialistas, deveriam ser examinados por um comitê de cirurgiões ${ }^{5}$ antes que se lhes permitisse exercer a profissão em Paris e em sua volta. Este exame foi criado pois "havia muitos charlatões na Europa, os quais sem nenhuma qualificação, não tinham dificuldade nenhuma de atrair clientes" (RING, 1998:157).

Percebe-se, assim, uma certa inquietação por parte das autoridades com os trabalhos prestados por pessoas consideradas despreparadas, demonstrando a necessidade de se impor algum tipo de regulamentação no exercício profissional. Conseqüentemente, pode-se pensar que existia, também, uma preocupação com a formação dos que praticavam a Odontologia, uma vez que a regulamentação visava "afastar" os "despreparados" da execução da atividade.

Além disso, Ring (1998) chama a atenção para o fato de que o desenvolvimento da Odontologia moderna também está relacionado com acontecimentos da França do século XVIII e com a figura do cirurgião Pierre Fauchard ${ }^{6}$.

Segundo Carvalho (2003), a partir desta época, houve uma maior preocupação das

${ }^{3}$ De acordo com SHEIHAM, A. Why free sugars consumption should be below $15 \mathrm{~kg}$ per person per year in industrialised countries: The dental evidence. Br. Dent. J. v. 171, p. 63-65, 1991. apud FREIRE (200, p. 262) “a quantidade de sacarose compatível com a saúde dentária estaria em 15kg por pessoa por ano em regiões beneficiadas com flúor e de $10 \mathrm{~kg}$ por pessoa por ano em regiões não cobertas pelo flúor.”

${ }^{4}$ Chama-se a atenção para a influência da Revolução Industrial e do processo de urbanização na expansão do consumo de açúcar pelas massas, uma vez que este passa a ser um dos principais ingredientes de ingestão calórica da classe trabalhadora (MINTZ, 1986 apud CARVALHO, 2003:43).

${ }^{5}$ Nesta época, a cirurgia era um dos campos que refletia a superioridade da França, enquanto nação mais culta e civilizada da Europa. A medicina era considerada apática e atrasada em relação à cirurgia (RING, 1998).

${ }^{6}$ Pierre Fauchard nasceu no ano de 1678. Formou-se como cirurgião-militar e se instalou em Paris por volta de 1719. Teve o mérito de unificar e ordenar tudo o que se sabia sobre Odontologia no ocidente, beneficiando, desta maneira, todos os profissionais desta especialidade. Morreu no ano de 1761 (RING, 1998). 
pessoas com a estética e com a elegância. Esta mudança no comportamento social foi acompanhada do surgimento de uma variedade de produtos e de técnicas para os que praticavam a arte dental ${ }^{7}$.

Desta maneira, não bastava mais resolver somente o problema da dor de dente por meio das extrações, como acontecia no século XVII. Tornava-se importante, agora, "repor os dentes" que faltavam, mas quem ditava esta necessidade era a vaidade e não a idéia de função vital dos elementos dentais (WOODFORDE apud CARVALHO, 2003). Ademais, a reposição dos dentes estava restrita às pessoas que podiam pagar pela "mercadoria" (no caso, os dentes), ou seja, esteve circunscrita aos segmentos mais ricos. Para as pessoas desprovidas de riquezas, as extrações continuavam sendo a opção de escolha para os "problemas de dente" (CARVALHO, 2003).

No ano de 1728, na França, foi publicado o livro "Tratado dos Dentes" (Le chirurgien dentiste ou Traité des Dents) ${ }^{8}$, de Pierre Fauchard. Esta obra é tida como um marco dentro da Odontologia moderna, sendo seu autor considerado o responsável pela criação da profissão de "cirurgião-dentista". Isto aconteceu porque foi Fauchard quem teria separado a Odontologia do campo mais amplo da cirurgia e, sobretudo, do ofício dos saca-molas, feito que o tornou conhecido como o "Pai da Odontologia" (RING, 1998).

Assim, a Odontologia, na França, passa a ser equiparada a uma profissão independente, "com seu próprio campo devidamente circunscrito de deveres e serviços e seu próprio nome" (RING, 1998:166). Fauchard acreditava que a separação da Odontologia provocaria uma melhora do nível profissional, pois muitos dos barbeiros e cirurgiões da época eram considerados despreparados (RING, 1998; FREITAS, 2001). Assinalou, ademais, que "a maior parte dos 'especialistas em Odontologia' não possuíam sequer um conhecimento médio" (RING, 1998:160). A profissão havia se organizado, inicialmente, em torno dos cirurgiões-barbeiros.
Segundo Ring (1998) foi o próprio "Pierre Fauchard quem cunhou a expressão cirurgião-dentista" (RING, 1998:166), que é como os franceses chamam seus dentistas ainda hoje. Depreende-se, desta forma, a importância que os acontecimentos da França e Pierre Fauchard, particularmente, tiveram no surgimento da profissão e na unificação e no ordenamento de conhecimentos que beneficiaram todos os profissionais da especialidade odontológica.

Pode-se dizer que desde o início do desenvolvimento da atividade odontológica predominaram as tarefas manuais, relacionadas com a extração e a reposição de dentes, ou seja, a "arte dental", a qual representava uma função muito mais artesanal e manual do que científica (CARVALHO, 2003). Assim, de acordo com esta autora, sugere-se que não foi um único grupo de praticantes o responsável pelo surgimento da profissão odontológica, sendo possível observar, principalmente a partir da metade do século XVIII, vários grupos de praticantes da "arte dental", tais como: barbeiros, ferreiros, ourives, relojoeiros, boticários, cirurgiões, médicos, etc. Muitos destes exerciam a Odontologia como atividade complementar à sua de origem; já outros se tornaram dentistas em tempo integral (CARVALHO, 2003).

Embora a França tenha sido o berço da Odontologia moderna, durante o século XIX a liderança neste campo passou para os Estados Unidos ${ }^{9}$. Ao analisar a atividade dos dentistas americanos da primeira metade do século XIX, Carvalho (2003) destaca que havia dois tipos de dentistas: (1) aqueles com formação empírica ou mecânica, os quais representavam o grupo maior, e que eram vistos como "tiradentes" e como "comerciantes de dentes artificiais", cuja formação caracterizava-se pelo empirismo, limitada especialização e trabalho essencialmente mecânico; e (2) aqueles com formação profissional ou científica, em um grupo bem menor, composto basicamente por médicos, os "científicos" (CARVALHO, 2003).

Esta autora destaca que a Odontologia, no século XIX, esteve dividida entre os que defendiam a "arte dental" e os defensores da "ciência dental" (CARVALHO, 2003). Conformou-se, assim, uma verdadeira disputa interna na Odontologia, quando "algumas lideranças odontológicas radicalizavam em torno da abordagem científica enquanto que outras acreditavam que a habilidade e a destreza manuais eram categorias que, de fato, sustentavam a credibilidade do trabalho odontológico" (CARVALHO, 2003:55).

Como os dentistas estavam em busca do reconhecimento profissional (principalmente em relação à profissão médica) e social (em relação à sua credibilidade pública) foram travadas frentes de batalha pela igualdade com a profissão médica e pela supremacia aos charlatões (CARVALHO, 2003).

A elevação da qualificação dos dentistas se daria por meio da formação destes profissionais nos mesmos moldes dos médicos, ou seja, através das ciências médicas, como a anatomia, a fisiologia, a patologia, a cirurgia e a terapêutica. Os dentistas esforçaram-se, então, em construir a idéia de que uma sólida formação, baseada na ciência, seria indispensável para a prática da Odontologia (CARVALHO, 2003).

Em 1840 foi criada a primeira escola de Odontologia do mundo, o "Baltimore College of Dental Surgery" na cidade de Baltimore, nos Estados Unidos. Há consenso de esta tenha sido a primeira escola, porque na Europa os conhecimentos sobre Odontologia eram ministrados em faculdades de Medicina, em seguida à formação médica (PERRI DE CARVALHO, 1995).

A criação de instituições formadoras teve como finalidade ultrapassar as metáforas de "arte mecânica" vinculadas à Odontologia, tornando-a científica e, portanto, equiparando-a à Medicina e, assim, conseguindo respeito e credibilidade por parte dos profissionais médicos e da opinião pública. Além disso, visava atingir os irregulares que atuavam na Odontologia (charlatões e empíricos), tentando afastá-los e dificultando seu ingresso na profissão (CARVALHO, 2003). Pode-se dizer, então, que a Odontologia somente "aparece como uma profissão moderna e independente, em meados do século dezenove, época em que foram estabelecidas as primeiras organizações profissio-

\footnotetext{
${ }^{7}$ Utiliza-se o termo "arte dental", pois o trabalho realizado pelos que se dedicavam aos serviços odontológicos, nesta época, estava mais relacionado com as habilidades manuais, típicas de um artesão, e que se baseavam no conhecimento empírico (a Odontologia ainda não havia agregado "cientificidade"). Desta forma, é possível diferenciar a "arte dental" (baseada no trabalho manual e nas habilidades de um artesão) da "ciência dental" (baseada em conhecimentos científicos, como as ciências médicas) (CARVALHO, 2003).

${ }^{8}$ Esta obra magna de Pierre Fauchard tinha 863 páginas em dois volumes, sendo "o livro mais importante sobre Odontologia surgido até aquela data e iria permanecer como uma autoridade até o século seguinte" (RING, 1998:160). Fauchard cobriu todo o campo da Odontologia, escrevendo sobre anatomia e morfologia dental, anomalias dos dentes, causas e prevenção da cárie dental, patologia oral, odontologia conservadora e protética.

${ }^{9}$ Dentre as razões para esta mudança destacam-se (RING, 1998): a suspensão temporária do avanço das ciências na França pelo caos trazido pela revolução; o espírito de investigação se arraigou na jovem nação americana; os dentistas profissionais do velho mundo vão aos Estados Unidos pela possibilidade de carreira e de obter ganhos; e a literatura odontológica cresceu muito em volume e importância nos Estados Unidos: entre 1800 e 1840 foram publicados 44 tratados neste país.
} 
nais-escolas, associações e jornais" (CARVALHO, 2003, p. 33). A partir daí estavam alicerçadas as bases para o desenvolvimento da profissão.

Segundo Pinto (2000), o século XX vivenciou o desenvolvimento de uma Odontologia capaz de oferecer, com qualidade, alternativas técnicas de crescente sofisticação e praticidade para solucionar os problemas de saúde bucal (incluídos aí os mais complexos) dos seus clientes.

\section{ASPECTOS DA HISTÓRIA DA ODONTOLOGIA NO BRASIL}

A primeira vez que o termo "dentista" foi mencionado nos documentos oficiais brasileiros foi no "Plano de Exames" da Junta do Protomedicato ${ }^{10}$ (PERRI DE CARVALHO, 1995; CARVALHO, 2003), o qual foi editado no ano de 1800, prevendo que, a partir daquela data, seriam aplicados exames para "cirurgiões herniários, dentistas e sangradores" (CUNHA, 1952:72 apud CARVALHO, 2003:99).

Com a vinda da família real portuguesa, em 1808, foram criadas as primeiras escolas de cirurgia no Brasil ${ }^{11}$, a Escola de Cirurgião no Hospital São José, na Bahia e a Escola Anatômica Cirúrgica e Médica no Hospital Militar e da Marinha, no Rio de Janeiro.

De acordo com Perri de Carvalho (1995) a primeira carta de dentista ${ }^{12}$ foi expedida no ano de 1811. Destaca-se que, nesta época, a "arte de tirar dentes" era executada principalmente por sangradores e barbeiros, ou seja, pessoas que não tinham uma educação formal.

Aos poucos começaram a se estabelecer no Brasil, principalmente na cidade do Rio de Janeiro, dentistas formados em escolas européias, com destaque aos franceses (em meados do século XIX). Somente por volta do ano 1840 é que se estabeleceu, na cidade do Rio de Janeiro, o primeiro dentista formado nos Estados Unidos, Clinton Van Tuyl.

Mais tarde, em 1849, este dentista, Clinton Van Tuyl, teve o mérito de publicar o primeiro livro sobre Odontologia no Brasil, intitulado de "Guia dos Dentes Sãos", o qual abordava algumas moléstias da boca e seus respectivos tratamentos, desde a infância até a velhice (PERRI DE CARVALHO, 1995).
A partir do ano de 1851 o Estatuto das faculdades de Medicina do Brasil previa um exame para os dentistas. Este exame, no entanto, foi visto como incipiente, uma vez que não era exigida uma preparação maior por parte dos candidatos e o aprendizado dos aspirantes continuava sendo aquele fora dos ambientes escolares, ou seja, junto aos dentistas que já exerciam a atividade. No ano de 1854, por meio de outra reformulação do Estatuto da Faculdade de Medicina do Rio de Janeiro é que foram incluídos os exames para os pretendentes à profissão de dentista (PERRI DE CARVALHO, 1995).

A regulamentação do exercício profissional da Odontologia no Brasil aconteceu por meio do Decreto No 1.764 , de 14 de maio de 1856. Até então, eram realizados "exames" para os dentistas e para os sangradores que quisessem se habilitar a fim de exercer a profissão, conforme descrito anteriormente (PERRI DE CARVALHO, 1995). O engajamento dos profissionais era feito pela concessão do título àqueles que recebiam um aprendizado informal, dentro de uma prática artesanal (FERNANDES NETO, 2003).

No ano de 1869 surgiu a "Arte Dentária”, primeira revista de Odontologia do país, a qual foi fundada pelo dentista João Borges Diniz, formado pela Faculdade de Medicina do Rio de Janeiro.

O Decreto $\mathrm{N}^{\mathrm{o}} 7.247$, de 19 de abril de 1879 , definiu que ficavam anexos, às faculdades de Medicina, uma escola de Farmácia, um curso de Obstetrícia e outro de "Cirurgia Dentária". Surgia, desta forma, um curso específico destinado para aqueles que se dedicavam à "arte dentária". Em 4 de julho de 1879 , a Decisão do Império $\mathrm{N}^{\circ} 10$ estabelecia que aos aprovados no curso de "Cirurgia Dentária", seria atribuído o título de "cirurgião-dentista" (PERRI DE CARVALHO, 1995).

Somente no início da década de 1880 , é que começou a ser formalizado o ensino da Odontologia no país, por meio da legislação que criou os Laboratórios de Cirurgia e Prótese Dentárias nas Faculdades de Medicina da Bahia e do Rio de Janeiro, através da Lei Orçamentária No 3.141 , de 30 de outubro de 1882.

Posteriormente, em 25 de outubro de 1884, ou seja, quase meio século após a criação da Escola de Odontologia de Balti- more, foi oficialmente instituído o ensino odontológico no Brasil, através do Decreto No 9.311 do Governo Imperial. Isso foi possível em função da chamada "Reforma Sabóia", desenvolvida pelo diretor da Faculdade de Medicina do Rio de Janeiro, Visconde Sabóia.

$\mathrm{O}$ ensino foi vinculado, inicialmente, às Faculdades de Medicina do Rio de Janeiro e da Bahia. No entanto, mesmo que os cursos estivessem localizados em faculdades de Medicina, a exemplo do que acontecia na Europa, no Brasil não existiam disciplinas comuns entre estes cursos (PERRI DE CARVALHO, 1995).

Já no século XX, no ano de 1919, o Decreto de Delfim Moreira estabeleceu a criação de cursos superiores de Odontologia com quatro anos de duração. No entanto, foi apenas no ano de 1933, ou seja, passados quatorze anos deste decreto, de 1919, que os cursos de Odontologia tornaram-se autônomos, isto é, que eles desligaram-se da tutela das escolas médicas, o que facultou a alguns cursos a criação de disciplinas além das obrigatórias (FERNANDES NETO, 2003).

De acordo com Freitas (2001), no ano de 1959, existiam trinta e três cursos de Odontologia no Brasil, sendo que destes apenas oito possuíam algum tipo de biblioteca e mais da metade deles (65\%) não ofereciam disciplinas de Higiene e Odontologia Social (tendo como fonte o Relatório CAPES), caracterizando um ensino defasado e carente de reformas. Desta forma, observa-se que a Odontologia brasileira "se estabelece como uma profissão técnica, se firma enquanto prática e não como ciência, e só muito posteriormente se preocupará em tornar-se científica" (FREITAS, 2001:38).

Percebe-se, assim, que a profissão odontológica no Brasil se desenvolveu, desde o início, de forma independente da Medicina (CARVALHO, 2003). Ela possui regulamentação própria através da Lei 4.324 , de 14 de abril de 1964, a qual instituiu os Conselhos Federal e Regionais de Odontologia, e através da Lei 5.081, de 24 de agosto de 1966, que regulamenta o exercício da Odontologia no país. O Decreto 68.704/71 regulamentou, posteriormente, a Lei 4.324/ 64 (CARVALHO, 2003).

\footnotetext{
${ }^{10}$ A Junta do Protomedicato foi criada em 1782, em substituição aos cargos de físico-mor e de cirurgião-mor, os quais eram responsáveis pelo licenciamento das atividades. Esta Junta estava composta de médicos e de cirurgiões aprovados, os quais tinham a função de fiscalizar o exercício das atividades ligadas à "arte de curar". No entanto, esta junta teve pouca duração, pois com a vinda de Dom João VI as funções passaram novamente para um cirurgião-mor, um físico-mor e seus delegados. Na época, os candidatos às atividades obtinham o licenciamento por meio de exames (PERRI DE CARVALHO, 1995:1; CARVALHO, 2003: 98). Para maiores informações, consultar Carvalho (2003). ${ }^{11}$ De acordo com Carvalho (2003:99) estas escolas de cirurgia foram transformadas em escolas de Medicina em 1832 (até então, não existiam essas escolas no Brasil).

${ }^{12}$ Correspondia a primeira carta de licença expedida no Brasil: expressava o direito de "tirar dentes" não mencionando em outros serviços bucais (CARVALHO, 2003:103).
} 
O título fornecido ao aluno concluinte de curso, faculdade oficial ou reconhecida de Odontologia no Brasil é o de "cirurgião-dentista". O diploma do egresso deve ser registrado junto ao Ministério da Educação (MEC) e, depois, o profissional deve se inscrever no Conselho Regional de Odontologia de seu Estado (CRO) a fim de que possa exercer, dentro dos princípios regulamentares e éticos, a profissão de cirurgião-dentista.

\section{PROBLEMATIZANDO \\ ALGUMAS DIMENSÕES DO MOMENTO VIVENCIADO PELA ODONTOLOGIA BRASILEIRA ATUAL: AVANÇOS E LIMITES}

Tendo em vista as mudanças de natureza social, econômica, cultural e tecnológica, bem como as modificações nas políticas de educação e de saúde, experimentadas nas últimas duas décadas no cenário nacional, salienta-se a importância de se discutir o estágio atual da profissão odontológica, não perdendo de vista os acontecimentos passados, anteriormente descritos no texto, mas refletindo sobre algumas dimensões do presente, com o intuito de fornecer subsídios para se pensar sobre seu possível comportamento futuro.

A Odontologia, ao longo de seu processo histórico como profissão, deu origem à conformação de um modelo de prática odontológica. Este modelo de prática pode ser entendido como resultado de vários fatores, dentre os quais: o contexto histórico; o padrão de desenvolvimento social e econômico; as necessidades da população; a influência do saber biomédico (ou seja, das ciências médicas); as recomendações e apontamentos dos decretos, dos pareceres e das legislações específicas; as diferentes formas assumidas pelos currículos nos cursos; e, também, pelas influências dos avanços em ciência e em tecnologia, estando incluídos aí os interesses das indústrias de materiais, de medicamentos e de equipamentos.

Assim sendo, afirma-se que são inegáveis os avanços agregados pela Odontologia brasileira ao longo das últimas décadas. $\mathrm{O}$ desenvolvimento de pesquisas sobre materiais, equipamentos e instrumentos, principalmente a partir da metade do século $\mathrm{XX}$, em vários países do mundo, possibilita, no momento atual, a prática de um atendimento odontológico ergonomicamente embasado, pautado em princípios de biossegurança e cientificamente comprovado, com maior conforto, precisão e qualidade, tanto ao profissional quanto ao paciente.

A extrapolação desses avanços para a classe odontológica em geral, entretanto, pode ser tendenciosa, na medida em que ela está na dependência de múltiplas variáveis, as quais compreendem tanto a dimensão global (social, política, econômica e científica) quanto a dimensão individual (pessoal). Estas variáveis englo- bam, por exemplo, desde a própria sustentação científica até a possibilidade ou não de acesso, por parte dos cirurgiões-dentistas, aos constantes conhecimentos que são gerados e disponibilizados na contemporaneidade.

Outro fator importante, nesta mesma linha de raciocínio, aponta para a premência de respeito aos princípios éticos e para a necessidade de comprometimento dos profissionais com a melhoria das condições de saúde da população. Respeito esse que, de acordo com Lunardi e cols. (2004), pode ser evidenciado na relação ética do profissional de saúde em vários níveis: consigo mesmo; com a profissão que exerce; com as instituições que atua; com os colegas trabalhadores; e, em última instância, com os pacientes. Salienta-se, também, que o comprometimento pode (e deve) ser visualizado diferentemente para os cirurgiões-dentistas que trabalham na esfera pública e para aqueles que trabalham em clínica privada, uma vez que distintas relações entre os profissionais e as suas respectivas instituições interferem nas suas condutas e nas suas posturas.

No entanto, independentemente da esfera de atuação dos cirurgiões-dentistas (se na pública ou na privada), atenta-se para um maior acesso a dados, a informações e a conhecimentos sobre a produção científica em torno da saúde bucal, através do desenvolvimento e do aprimoramento das tecnologias de informação e de comunicação (num sentido de educação informal), bem como através de congressos, de cursos de atualização, de aperfeiçoamento e de especialização (num sentido de educação continuada), grandemente ofertados por faculdades e por centros de ensino e pesquisa em Odontologia, os quais, inclusive, proliferam-se em velocidade acelerada no território nacional.

A divulgação de resultados de trabalhos científicos e de pesquisas, tanto em meios impressos, quanto em meios eletrônicos, possibilita que os cirurgiões-dentistas (ao menos os interessados) possam manter sua atualização e, até mesmo, aprimorar sua práxis profissional. $\mathrm{O}$ acesso à Internet permite que milhares de artigos, de estudos, de pesquisas, de textos, de reportagens e demais materiais sejam apropriados com rapidez e facilidade neste início de século XXI, especialmente quando se compara o momento vivenciado em relação às décadas anteriores.

As pesquisas constantes para a fabricação de materiais odontológicos com propriedades biológicas, químicas e físicas melhoradas, bem como o desenvolvimento de técnicas adequadas aos progressos experimentados na indústria de materiais e de medicamentos têm propiciado que tratamentos sejam realizados com maior conservação das estruturas dentais, com precisão da abordagem, com durabilidade, com qualidades estéticas e com maiores conforto, segurança e satisfação para os pacientes e para os cirurgiões-dentistas.
Simultaneamente, o desenvolvimento da ergonomia em Odontologia traz melhorias aos processos de trabalho e à relação homem-máquina-ambiente no consultório odontológico (BARROS, 1991). Observa-se, além disso, que as indústrias de equipamentos odontológicos, de certa forma 'pressionadas' pelos avanços em pesquisas vêm lançando, continuamente, novas tendências em espaços e em equipos ergonomicamente corretos.

Em que se pesem todos estes aspectos, aqui interpretados como 'avanços', chama-se a atenção para que esta visão (podendo ser interpretada por alguns como demasiado positiva) tem como finalidade exemplificar algumas possibilidades de melhorias para o 'agir' odontológico, as quais podem estar passando desapercebidas por uma grande massa de cirurgiões-dentistas no país, tanto pelos 'custos' da incorporação de tais avanços, quanto pela postura individual frente a inovações e a mudanças, pois estas, invariavelmente, envolvem tensão e resistência.

Sem perder de vista as idéias expostas até aqui, mas, retrocedendo um pouco na dimensão histórico-temporal e focalizando na organização da atividade laboral, evidencia-se que, ao longo do tempo, os profissionais da Odontologia vieram se estruturando em torno do atendimento a pequenos grupos populacionais, isto é, em torno da clientela, adscrita, que procurava por atendimento dentário.

Como reflexo desse modo de organização da profissão, percebe-se, cada vez mais, na Odontologia brasileira deste início do século XXI, uma grande quantidade de cirurgiões-dentistas dotados de capacidade técnica e disponibilidade tecnológica, voltados para os pacientes que podem pagar pela assistência prestada, mas estes são em número cada vez menor (FREITAS, 2001). Este contexto clarifica o modelo do profissional liberal, significando que o cirurgião-dentista é formado e atua no sentido de oferecer certos tipos de trabalhos em troca de um pagamento determinado.

Neste mesmo sentido, Pinto (2000), coloca a idéia de que a prática odontológica se encontra fundamentada em um modelo de organização, o qual com frequiência, acaba por "concentrar a oferta de serviços junto aos grupos de média e alta renda, daí resultando o estreitamento do alcance dos avanços tecnológicos que terminam por beneficiar apenas os setores economicamente mais favorecidos da população" (PINTO, 2000:2).

Fica evidente, deste modo, a contradição entre os desejos de lucro de uma classe profissional fundamentalmente liberal e o poder aquisitivo das largas camadas da população (VALENÇA, 1998). Ainda, conforme assinalado por Botazzo (2000), muitos candidatos ao título de cirurgiões-dentistas, buscam obter prestígio e fazer 'fortuna' com a profissão. 
De acordo com o Relatório Final da I Conferência Nacional de Saúde Bucal (1986) o modelo atual de prática odontológica "cobre as necessidades de somente $5 \%$ da população" (BRASIL, 1986). Além disso, este relatório destaca outras características desse modelo de prática: (1) a concentração de profissionais nos grandes centros urbanos, inclusive nos serviços públicos neles localizados; (2) a pouca utilização de pessoal auxiliar de nível elementar e médio; (3) a quase inexpressiva utilização, de forma sistematizada, de métodos preventivos de caráter coletivo; (4) a falta de democratização de conhecimentos e de informações sobre saúde bucal à população; (5) a tendência de se valorizar a especialidade em detrimento da clínica geral; (6) a proliferação de faculdades de Odontologia, com queda do nível de ensino; e, por fim, (7) a inadequação do profissional formado às necessidades da comunidade e à realidade social em que vive (BRASIL, 1986).

Pinto (1993) coloca que a Odontologia, "habituada ao atendimento direto com o paciente e aos programas de saúde pública para pequenas comunidades, em geral de escolares, descobriu que esse tipo de prática não conseguiu melhorar ou sequer manter estáveis os níveis de saúde bucal dos brasileiros" (PINTO, 1993:2), vendo-se envolvida numa crise geral, onde seu modelo de ação (liberal por natureza) passa a ser contestado.

Este modelo é tido como ineficaz na medida em que não responde à resolução, ou redução em níveis significativos, dos problemas de saúde bucal da população e é ineficiente uma vez que é de alto custo e baixo rendimento. Percebe-se, ainda, a inadequação em relação ao preparo dos recursos humanos em nível superior, uma vez que estes são formados de maneira desvinculada das reais necessidades do país, precocemente direcionados para as especialidades e bastante dissociados das características dos serviços onde deverão (ou poderão) atuar (BRASIL, 1986; VALENÇA, 1998).

O modelo de prática odontológica no Brasil, na visão de Botazzo (2000), se encontra à beira da exaustão, em que a profissão literalmente se encontra "metida num beco" (BOTAZZO, 2000:23). Assim, este esgotamento se confirma pelas crescentes afirmações de incompetência social e epidemiológica (BOTAZZO, 2000).

$\mathrm{O}$ país possui um gigante contingente de cirurgiões-dentistas e, ao mesmo tempo, de acordo com o Relatório Final da I Conferência Nacional de Saúde Bucal (1986) "a situação de Saúde Bucal, da população brasileira, é Caótica" (BRASIL, 1986, p. 4).

Segundo Pinto (1993), no ano de 1980, o Brasil contava com 61.628 cirurgiões-dentistas inscritos nos Conselhos Regionais de Odontologia (CROs). Em 1989 este número subiu para 101.880 profissionais. Ou seja, num período de dez anos (1980-1989) "o estoque de profissionais cresceu extraordinariamente na ordem de $65,3 \%$ ao passo que a população brasileira aumentava em 20\%" (PINTO, 1993:37-38).

Em 1992, cerca de 11\% dos dentistas de todo o mundo estavam no Brasil (PINTO, 1993; NARVAI, 2002). Freitas (2001) cita que, neste mesmo ano de 1992, existiam cerca de 123 mil cirurgiões-dentistas e 84 Cursos de Odontologia, "o maior número de cursos existentes em qualquer país" (FREITAS, 2001:41).

No ano de 2003 existiam mais de 183 mil cirurgiões-dentistas inscritos no Conselho Federal de Odontologia (CFO). Para este mesmo ano, a soma de faculdades chegou a 161, ou seja, foi praticamente dobrado o número de escolas odontológicas em menos de quinze anos (1992-2003). De acordo com o Censo da Educação Superior de 2003 (MEC), estavam matriculados, naquele ano, 46.915 alunos em faculdades de Odontologia (BRASIL, 2003).

Os dados de 2005 demonstram que estavam cadastradas 174 faculdades no Conselho Federal de Odontologia (CFO, 2005). Para o início do ano de 2007 os dados do CFO sinalizam para a existência de 212.262 cirurgiões-dentistas registrados (CFO, 2007).

Há um grande paradoxo: apesar da grande quantidade de profissionais, a população brasileira apresenta uma prevalência muito alta de doenças bucais. Pode-se observar que há uma grande discrepância entre o avanço tecnológico e científico da Odontologia brasileira e os níveis de saúde bucal da população (BRASIL, 1993).

Ao traçar o perfil epidemiológico de saúde bucal no Brasil entre os anos de 1986 e 1996, Roncalli (1999) conclui que é possível afirmar que está acontecendo um declínio de cárie no país, sendo isto comprovado através dos dados nacionais (apesar das suas limitações), bem como por meio de estudos que vêm sendo realizados isoladamente em vários Estados.

Weyne (1999), referindo-se ao quadro das doenças bucais no Brasil, afirma que a situação ainda é preocupante, pois crianças e adolescentes continuam exibindo elevados índices de cárie e doença periodontal e muitos adultos e idosos, em conseqüência dos resultados avançados dessas patologias e dos desfavoráveis condicionantes econômicos, sociais e culturais "não conseguem manter mais do que alguns dentes na boca" (WEYNE, 1999:7), o que os leva a necessidade de uso de extensas próteses e dentaduras. Este mesmo autor acrescenta que "continuamos vivendo um velho e irresolvido paradoxo metafísico em relação à saúde bucal: temos muito menos doença, mas ainda continuamos com muitos doentes" (WEYNE, 1999:21).
Embora não seja questionada a importância da saúde bucal como condição indispensável para o bem viver cotidiano, observa-se que uma parcela considerável da população brasileira não tem acesso aos serviços odontológicos (PNAD, 1998; PROJETO SB 2003).

De acordo com os dados da Pesquisa Nacional por Amostragem de Domicílios (PNAD/ 98), é possível se afirmar que, de uma população residente de aproximadamente $160 \mathrm{mi}$ lhões de brasileiros para o ano de 1998, mais de 29 milhões deles nunca tinham consultado um cirurgião-dentista (IBGE, 2004).

Barros e Bertoldi (2002), ao analisarem os microdados disponíveis pela PNAD/ 98, afirmam que, do total de entrevistados, $19 \%$ declararam nunca ter consultado um cirurgião-dentista (sinalizando, desta maneira, para os mais de 29 milhões de brasileiros desassistidos). Neste sentido, observou-se que $77 \%$ das crianças de $0-6$ anos de idade nunca haviam consultado um profissional da Odontologia. Para os adultos (20-49 anos) essa percentagem foi de 4\%. Entre estes adultos, comparando-se os $20 \%$ mais pobres com os $20 \%$ mais ricos "observou-se que o número de desassistidos era 16 vezes maior entre os primeiros" (BARROS; BERTOLDI, 2002 , p. 709), ou seja, naqueles $20 \%$ mais pobres. Já, no grupo de 0-6 anos, as crianças mais ricas consultaram o dentista, no ano anterior à entrevista, cinco vezes mais do que as pobres. Ficou evidenciado, também, que existe uma grande desigualdade no acesso e na utilização dos serviços odontológicos entre os mais pobres e os mais ricos.

De acordo com os resultados do Projeto SB 2003, divulgado em 2004, cerca de $14 \%$ dos adolescentes brasileiros (grupo etário de 15 a 19 anos) nunca foram ao cirurgião-dentista. Evidencia-se, deste modo, que a Odontologia, continua não chegando a muita gente, gente essa que, na sua quase totalidade, provavelmente esteja necessitando de cuidados em saúde bucal. Pode-se afirmar que grande parte da Odontologia continua restrita aos consultórios particulares e por isso 'fechada' para uma parcela razoável do povo brasileiro.

Em conformidade com o exposto anteriormente, salienta-se que mudanças ocorridas na sociedade brasileira, no âmbito do sistema de saúde e nas políticas de saúde e de educação, passaram a influenciar substancialmente o mercado de trabalho em saúde, bem como os processos de trabalho dos profissionais que atuam (ou que pretendem vir a atuar) na esfera pública.

Nesse sentido, a criação do Sistema Único de Saúde (SUS), na Constituição Federal de 1988, se traduz em um importante fator a ser levado em consideração neste processo, na medida em que o SUS trouxe avanços conceituais e no desenho da política de saúde. 
O Programa Saúde da Família (PSF), no âmbito do SUS, criado no ano de 1994, é apontado, hoje, como a principal estratégia do Ministério da Saúde para a reorganização da atenção básica. Uma das grandes contribuições introduzidas pelo PSF foi uma visão ativa da intervenção em saúde, a de não 'esperar' a demanda 'chegar' para intervir, mas de agir sobre ela preventivamente. Além disso, ele trouxe as concepções de integração com a comunidade e de um enfoque menos reducionista sobre a saúde (VIANA; DAL POZ, 1998).

O PSF busca a reorganização da prática assistencial em novas bases e critérios, em substituição ao modelo tradicional de assistência. Desde 2001, a saúde bucal foi incluída no PSF, tendo como objetivos "melhorar as condições de saúde bucal da população", "orientar as práticas de atenção à saúde bucal", bem como "ampliar o acesso das famílias brasileiras às ações de saúde bucal" (BRASIL, 2001).

Deste modo, a inserção de Equipes de Saúde Bucal (ESB) no PSF amplia as perspectivas de mercado de trabalho para o cirurgião-dentista "despontando o serviço público como alternativa promissora" (SILVEIRA FILHO, 2002:37).

A conformação do SUS aponta, assim, para a necessidade de uma reestruturação na lógica que tradicionalmente vinha determinando a formação dos profissionais de Odontologia, fazendo necessário levar em consideração os princípios e diretrizes da política de saúde nacional, pois se contata que "a maioria dos profissionais de Odontologia que compõem os serviços públicos de saúde (...) desenvolvem uma prática tradicional em que o modelo privado de atenção é transferido acriticamente para a prática pública" (BRASIL, 1993).

Percebe-se, assim, uma preocupação a respeito da formação acadêmica dos cirurgiões-dentistas, uma vez que estes "são precocemente direcionados para as especialidades" (VALENÇA, 1998:14) e são formados para uma lógica diferente do SUS (VALENÇA, 1998).

No que diz respeito à Odontologia no SUS, destaca-se que a inserção das ações de saúde bucal torna-se indispensável para garantir a integralidade da atenção, uma vez que praticamente toda a população já apresentou ou apresenta doenças bucais, sendo as mais freqüientes a cárie dentária e a doença periodontal. Além disso, diante de todas as inovações nos conceitos e no desenho do PSF, percebese que os cirurgiões-dentistas necessitam de conhecimentos e habilidades adicionais (ou seja, uma formação comprometida com a Saúde Pública/Saúde Coletiva) para que possam atuar nos moldes desta estratégia, uma vez que esta se encontra em expansão.
Em complementaridade, há muitas propostas, no âmbito das políticas de educação, alertando para a necessidade de formação de um profissional generalista em Odontologia. Merecem destaque, neste contexto, as Diretrizes Nacionais Curriculares para os Cursos de Odontologia (PARECER CNE/CES 1300/ 01, RESOLUÇÃ̂O CNE/CES No 03/02). Estas diretrizes desencadearam processos de reforma curricular em todos os cursos e faculdades de Odontologia do Brasil, uma vez que se conformaram em orientações a serem, obrigatoriamente, incorporadas pelas instituições de ensino. Elas representaram um avanço na aproximação entre o Ministério da Saúde (MS) e o da Educação (MEC) no sentido de que enfatizam a formação de recursos humanos em saúde em conformidade com o conceito de saúde e os princípios do SUS.

Após esta ampla caracterização, com avanços, críticas e mudanças no mercado de trabalho e no sistema de saúde no Brasil, afirmase a necessidade de transformação do atual modelo hegemônico de prática odontológica. Há que se pensar sobre novos processos de trabalho que possibilitem uma atenção em saúde humanizada, com qualidade, conforto e segurança tanto para pacientes como para cirurgiões-dentistas. No âmbito do Sistema Único de Saúde, o modelo de atenção à saúde bucal deve ser orientado pelas propostas de universalidade do acesso, da integralidade e resolutividade das ações, com a inclusão de especialidades segundo o perfil epidemiológico da população, buscando, assim, a construção de uma atenção integral em saúde que leve à viabilização de uma nova prática em saúde bucal para a dignificação da vida e a conquista da cidadania (BRASIL, 1993).

Weyne (1999) destaca que "a Odontologia deve ampliar seus compromissos éticos com a sociedade e com o social" (WEYNE, 1999:24), de modo que as pessoas possam viver com saúde. Portanto, há que se instituir mudanças na forma tradicional de tratamento centrado na doença e até então hegemônica para um outro tipo de profissional, cuja ideologia é a prevenção das doenças e a promoção da saúde (WEYNE, 1999:5). Para tanto, torna-se fundamental incorporar os recentes conhecimentos sobre a etiologia, o diagnóstico e as possibilidades de tratamento para as doenças bucais, juntamente com aqueles que têm sido construídos/produzidos em outras Ciências (como os das Ciências Sociais e Humanas), pois eles podem trazer avanços importantes para a Odontologia, permitindo aos cirurgiões-dentistas uma atuação profissional mais ampla e qualificada na sociedade.

\section{COMENTÁRIOS FINAIS}

A análise dos aspectos históricos envolvidos no surgimento da profissão de cirurgiãodentista permite 'elucidar' fatos, os quais pos- sibilitam a experimentação de processos reflexivos não tão superficiais acerca do comportamento atual da Odontologia. Ficam evidentes, conforme anteriormente mencionado, avanços, retrocessos, contradições, disputas e questionamentos.

Ao observar o desenvolvimento da profissão, destacam-se acontecimentos da França do século XVIII e dos Estados Unidos, do século XIX. Salienta-se o caráter essencialmente artesanal e liberal na gênese da profissão. Neste sentido, a figura do cirurgião-dentista continua, ainda hoje, sendo bastante associada à atuação liberal, quando determinados serviços são oferecidos, limitados às quatro paredes do consultório dentário, em troca de pagamentos.

Chama-se a atenção que, em pouco tempo, houve avanços importantes em termos de agregação de cientificidade, de aprimoramento de técnicas, de materiais e de equipamentos, com consequiente melhoria dos tratamentos prestados.

Entretanto, face a estes pontos, algumas situações se colocam como obstáculos a serem ultrapassados, especialmente aqueles ligados ao modelo hegemônico de prática odontológica: as "precárias" condições de saúde bucal, associadas a uma demanda reprimida por cuidados de saúde; o acesso limitado de grande parte da população aos serviços; os custos dos tratamentos (incluídos custos de mão-de-obra, de materiais, de medicamentos e de equipamentos); a resolutividade das ações prestadas; o crescente contingente de egressos, tendo em vista a proliferação e cursos e faculdades no país; a concentração dos profissionais nos centros urbanos; e, dentre outros, a pertinência da incorporação de outros saberes, além do estritamente biológico.

Assim sendo, há a urgente necessidade de que estas questões sejam discutidas no interior da classe odontológica. Para tanto, torna-se indispensável a adoção de uma postura reflexiva/avaliativa por parte dos formuladores das políticas educacionais, das instituições formadoras de recursos humanos em saúde, das associações e das entidades de classe, bem como dos próprios profissionais cirurgiões-dentistas, que, em última instância, são os responsáveis pela prestação das ações de saúde bucal. A efervescência dessas discussões pode servir como uma potente mola propulsora para a superação de alguns dos dilemas que acompanham a Odontologia desde a sua origem.

\section{ABSTRACT}

This article's main objective is to revise and describe the happenings that are intrinsic to the genesis of the dental surgeon profession, elucidating up-to-date dimensions and unfoldments that surround the 'Dental Art'. 
With that, it is intended to reflect about the limitations and advancements of the dental praxis, questioning, at the same time, any aspects that interpose as difficulties to the consolidation of a health attention based on the principles of equity, humanization and integrality in health. The text, one of descriptiveinformative character, analyses events of dentistry's historical process in the occident and in Brazil specifically. Furthermore, it problematizes dimensions of the hegemonic model of dental practice, in the current national scenario, highlighting "critical knots", which have to be noticed, analyzed and confronted by the profession with certain urgency, as some of them are characterized as dilemmas that have come along with the profession since its beginning. The overcome of such dilemmatic situations becomes mandatory for the construction of a new posture on oral health and care and so that Dentistry can truly reach its objectives as a profession.

\section{KEYWORDS}

Dentistry. Profession. Dentistry's historical process. Hegemonic model of dental practice.

\section{REFERÊNCIAS}

BARROS, A.J.D; BERTOLDI, A.D. Desigualdades na Utilização e no Acesso a Serviços Odontológicos: Uma Avaliação em Nível Nacional. Ciência \& Saúde Coletiva, Rio de Janeiro, v.7, n.4, p. 709-717, 2002. .

BARROS, O.B. Ergonomia 1: A Eficiência ou Rendimento e a Filosofia Correta de Trabalho em Odontologia. São Paulo: Pancast, 1991.

BEZERRA, A.C.B; DE TOLEDO, O.A. Nutrição, Dieta e Cárie. In: KRIEGER, L. (Org.) Promoção de Saúde Bucal. São Paulo: Artes Médicas, 1999. Cap. 3, p. 43-68.

BOTAZZO, C. Da Arte Dentária. São Paulo: HUCITEC/FAPESP, 2000.

BRASIL. MINISTÉRIO DA EDUCAÇÃO. Parecer CNE/CES 1300/01. Diário Oficial da União, Brasília, 7 dez. 2001. Seção 1, p. 25 .

BRASIL. MINISTÉRIO DA EDUCAÇÃO. Resolução CNE/CES N³/2002. Diário Oficial da União, Brasília, 4 mar. 2002. Seção 1, p.10.

BRASIL. MINISTÉRIO DA EDUCAÇÃO. Instituto Nacional de Estudos e Pesquisas Educacionais. Censo da Educação Superior. Brasília, 2003.
BRASIL. MINISTÉRIO DA SAÚDE. Conferência Nacional de Saúde Bucal, I. Brasília, 1986.

BRASIL. MINISTÉRIO DA SAÚDE, 1993. Conferência Nacional de Saúde Bucal, II. Brasília, 1993.

BRASIL. Portaria No 267/GM, de 6 de março de 2001. Brasília: Ministério da Saúde, 2001.

CARVALHO, C.L, 2003. Dentistas Práticos no Brasil: História de Exclusão e Resistência na Profissionalização da Odontologia Brasileira, 2003 (Doutorado em Saúde Pública)- Escola Nacional de Saúde Pública, Fundação Oswaldo Cruz, Rio de Janeiro.

CHAVES, M.M. Odontologia Social. Rio de Janeiro: Artes Médicas, 1986.

CONSELHO FEDERAL DE ODONTOLOGIA. Faculdades de Odontologia existentes no Brasil. Disponível em: < http:// www.cfo.org.br>. Acesso em dez. 2003.

CONSELHO FEDERAL DE ODONTOLOGIA. Faculdades de Odontologia existentes no Brasil. Disponível em: < http:// www.cfo.org.br>. Acesso em dez. 2005.

CONSELHO FEDERAL DE ODONTOLOGIA. Profissionais por CRO. Disponível em: < http:// www.cfo.org.br> . Acesso em fev. 2007.

FERNANDES NETO, A.J. A Evolução dos cursos de Odontologia no Brasil. Disponível em: < http:// www.cfo.org. br >. Acesso em dez. 2003.

FREIRE, M. do C. M. Dieta, Saúde Bucal e Saúde Geral. In: BUISCHI, Y. de P. (Org.) Promoção de Saúde Bucal na Clínica Odontológica. São Paulo: Artes Médicas: EAP-APCD, 2000. Cap. 10, p. 246-278.

FREITAS, S.F.T. de. História Social da Cárie Dentária. Bauru: EDUSC, 2001.

INSTITUTO BRASILEIRO DE GEOGRAFIA E ESTATÍSTICA. Pesquisa Nacional por Amostra de Domicílios (PNAD/ 1998). Disponível em: < http:// www.ibge. gov.br $>$. Acesso em mar. 2004.

IYDA, M. Saúde Bucal: Uma Prática Social. In: BOTAZZO, C.; FREITAS, S.F.T de (Org.) Ciências Sociais e Saúde Bucal: Questões e Perspectivas. Bauru/São Paulo: EDUSC/UNESP, 1998. Cap. 5, p.127-139.
LUCIETTO, D.A. Percepções dos Docentes e Reflexões sobre o Processo de Formação dos Estudantes de Odontologia. 238 f. 2005. Dissertação (Mestrado em Saúde Pública) - Escola Nacional de Saúde Pública Sergio Arouca, Fundação Oswaldo Cruz, Rio de Janeiro.

LUNARDI, V.L., et al. O cuidado de si como condição para o cuidado dos outros na prática de saúde. Rev. LatinoAmericana Enfermagem, Ribeirão Preto, v.12, n.6, p 933-939, nov./dez. 2004.

NARVAI, P.C. Odontologia e Saúde Bucal Coletiva. São Paulo: Santos, 2002.

PERRI de CARVALHO, A.C. Educação \& Saúde em Odontologia: Ensino da Prática e Prática do Ensino. São Paulo: Santos, 1995.

PINTO, V.G. A Odontologia Brasileira às Vésperas do Ano 2000: Diagnóstico e Caminhos a Seguir. São Paulo: Santos, 1993.

PINTO, V.G. Saúde Bucal Coletiva. São Paulo: Santos, 2000.

RING, M.E. História Ilustrada da Odontologia. São Paulo: Manole, 1998.

SILVEIRA FILHO, A.D. A Saúde Bucal no PSF: O Desafio de Mudar a Prática. Revista Saúde da Família, Brasília, v.6, p.36-43, 2002.

VALENÇA, A.M.G. A Educação em Saúde na Formação do CirurgiãoDentista: Da Necessidade à Prática Participativa. Niterói: Editora UFF, 1998.

VIANA. A.L.; DAL POZ, M. R. A Reforma do Sistema de Saúde no Brasil e o Programa de Saúde da Família. Physis Revista de Saúde Coletiva, Rio de Janeiro, v.8, n.2, p.11-48, 1998.

WEINE, S.de C. A Construção do Paradigma de Promoção de Saúde - Um Desafio para as Novas Gerações. In: KRIEGER, L. (Org.) Promoção de Saúde Bucal. São Paulo: Artes Médicas, 1999. Cap.1, p. 2-26.

Endereço para correspondência: deisonlucietto@hotmail.com tel: (51) 32112691 